University of Nebraska - Lincoln

DigitalCommons@University of Nebraska - Lincoln

Faculty Publications, Department of Child, Youth, and Family Studies

Child, Youth, and Family Studies, Department of

January 1978

\title{
SOCIAL EXPERIENCE AND MORAL JUDGMENT IN EAST AFRICAN YOUNG ADULTS
}

Carolyn P. Edwards

University of Nebraska-Lincoln, cedwards1@unl.edu

Follow this and additional works at: https://digitalcommons.unl.edu/famconfacpub

Part of the Family, Life Course, and Society Commons

Edwards, Carolyn P., "SOCIAL EXPERIENCE AND MORAL JUDGMENT IN EAST AFRICAN YOUNG ADULTS" (1978). Faculty Publications, Department of Child, Youth, and Family Studies. 36.

https://digitalcommons.unl.edu/famconfacpub/36

This Article is brought to you for free and open access by the Child, Youth, and Family Studies, Department of at DigitalCommons@University of Nebraska - Lincoln. It has been accepted for inclusion in Faculty Publications, Department of Child, Youth, and Family Studies by an authorized administrator of DigitalCommons@University of Nebraska - Lincoln. 
The Journal of Genetic Psychology, 1978, 133, 19-29.

\title{
SOCIAL EXPERIENCE AND MORAL JUDGMENT IN EAST AFRICAN YOUNG ADULTS*1
}

\author{
Harvard Graduate School of Education
}

\section{Carolyn Pope EdWards}

\begin{abstract}
SUMMARY
Relationships between stage of moral judgment and antecedent social experiences are presented for a non-Western sample of young adults. Crosssectional data are presented for two groups of Kenyan students: 52 University of Nairobi students; and 40 fourth form secondary school $S \mathrm{~s}$. Critical variables are $(a)$ family modernization, $(b)$ attending ethnically pluralistic secondary schools, and $(c)$ living independently away from home. The correlations between moral judgment stage and these three variables are controlled for, and compared to, correlations between stage of moral judgment and age, sex, race, and academic ability (as measured by standardized achievement tests or by grades). The evidence demonstrates associations between moral stage and all three critical variables, though in different ways for the two age levels of $S$ s.
\end{abstract}

\section{A. INTRODUCTION}

In cognitive-developmental theory, the development of moral reasoning depends on interaction between the child and the social environment $(11,15)$. Experience is conceived to stimulate moral development by $(a)$ providing role-taking opportunities and $(b)$ provoking an optimal amount of cognitive disequilibrium. Experimental research has established that both processes

* Received in the Editorial Office, Provincetown, Massachusetts, on December 27, 1976. Copyright, 1978, by The Journal Press.

${ }_{1}$ This study is based on a Doctoral dissertation presented to the Harvard Graduate School of Education, 1974. The research was conducted at the Child Development Research Unit, University of Nairobi, and was supported by grants from the National Institute of Mental Health (MH1096-18) and the Carnegie Corporation. The author would like to thank John and Beatrice Whiting, Elliot Turiel, and Lawrence Kohlberg for their support and assistance throughout the project.

Requests for reprints should be addressed to the author at the address shown at the end of this article. 
can lead to moral stage change $(13,18)$. Yet the experimental research does not clarify how these processes correspond to real-life experiences: little evidence exists to test whether real-life experiences with parents, peers, and the wider community do in fact influence the development of moral reasoning. Nonexperimental research is critical here because as Lickona (13) has noted, experiences of change, such a peer interaction, "do not readily lend themselves to being telescoped into a brief experimental session" (13, p. 239).

Piaget (15) first proposed that parents can stimulate the development of their children's moral judgment by encouraging independence of adult constraint. Four studies $(2,8,14,17)$ employing Kohlberg's methods have found significant relationships in the expected direction between parent-child interactional style or parental disciplinary methods and children's stage of moral reasoning.

Piaget (15) also proposed that peer reciprocity and cooperation can stimulate more complex moral reasoning. Studies employing Kohlberg's methods $(9,10)$ have found significant relationships between degree of social participation with peers and maturity of moral reasoning, but studies employing Piaget's methods $(12,16)$ have not done so.

Finally, Turiel (19) has argued for a third general type of social influence, experience with the wider community. Exposure to a diversity of individual and cultural values is hypothesized to promote transition from Kohlberg's conventional to principled levels. Although this proposal has not been explored by other investigators, Garbarino and Bronfenbrenner (5) have presented a parallel notion in their socialization (not cognitive-developmental) model of moral development.

The present study, based on research in Kenya, uses Kohlberg's methods to relate particular home and school experiences to the cognitive-moral development of Kenyan young adults. Three hypotheses are tested. First, students from more modernized backgrounds (indexed by parents' education) are expected to show higher levels of moral judgment than students from more traditional backgrounds, because modernized parents in Kenya are more likely to reason and negotiate issues with their children and less likely to expect unquestioning respect and obedience $(20,21)$. Second, students who have spent a relatively greater length of time living on their own away from home (boarding at school or youth hostels) are expected to show higher levels of moral judgment than students who have lived longer at home, because living away encourages independence of parent constraint and increases opportunity for interaction with peers (3). Third, students who have attended ethnically diverse secondary schools are expected to show more mature moral 
judgment than students who have attended culturally homogeneous schools, because the Kenyan "national" (racially and tribally mixed) schools expose students to a great diversity of values in a positive climate of mutual respect. Students there exchange much information with each other and often come to question many of their childhood values (3).

Two samples were studied: first, a heterogeneous university sample, and second, a highly controlled secondary sample. For both, the statistical predictive power of the three experiences listed above was compared to that of age and academic ability, both expected to relate positively to cognitive-moral development (11), and sex and racial group, neither necessarily expected to relate to cognitive-moral development (1).

\section{B. METHOD \\ 1. Subjects}

Students in sample 1 (university) were 35 male and 17 female University of Nairobi students interviewed in 1972-73. These students constitute a highly selected group intellectually because examinations allow only a small minority of aspiring secondary graduates to go on to the university. The $S \mathrm{~s}$ ranged in age from 19 to 31 and belonged to two racial groups (35 Black Africans, 17 Indo-Pakistani Asians). At the university they were first to fourth year students working toward bachelor's degrees in Arts, Medicine, Commerce, Engineering, Law, Education, and Science. $S \mathrm{~s}$ were recruited in classes or through personal contact and were paid seven shillings ( $\$ 1.00$ U.S.) for the interview.

$S$ s in sample 2 (secondary) were 20 male and 20 female students ranging in age from 16 to 21 from the fourth form of secondary school (approximately equal to U.S. tenth grade). They belonged to a single ethnic group, the Kikuyu (the largest tribal group in Kenya). These $S$ s had for four years attended one of seven secondary schools of excellent and approximately equal academic reputation located in Nairobi and Nyeri, two cities of Central Province. ${ }^{2}$ The students were selected so that $10 \mathrm{~S}$ s (five females, five males) fell into each of four categories defined by the two factors of school residence and ethnic diversity. In terms of residence, students attended either day or boarding institutions, defined by whether they lived at home or at school. In terms of

\footnotetext{
${ }^{2}$ The schools were Kimathi Government High, Nyeri High and Tumutumu Girls' High (located in Nyeri) and State House Road Girls' Secondary, Upper Hill School, Kenya High, and the Nairobi School (located in Nairobi). Students from an eighth school (H. H. Aga Khan High School in Nairobi) were also interviewed, but because language skills in English proved poor relative to other subjects, their interviews were not included in the analysis.
} 
ethnic diversity, their classmates were either homogeneous culturally (only Kikuyus and closely related groups) or racially and tribally pluralistic. The pluralistic schools showed a high degree of cultural diversity; they contained 64-72\% African students of various tribes, $24-34 \%$ Asian students, and 1-3\% students with a European or North American background (3). All $S$ s were interviewed at school. At the culturally homogeneous schools, $S \mathrm{~s}$ were randomly selected from class volunteers. At the heterogeneous schools, the headmasters named, from the target ethnic group, students of average school achievement.

\section{Procedure}

All $S$ s were interviewed in English by the author (English is the language used from first grade onward in the Kenyan school system). The $S$ s in sample 1 received an adapted version of the Kohlberg moral judgment interview: it contained new versions of three of the standard moral dilemmas (Stealing the Drug, Mercy Killing, the Father-Son Promise), as well as a fourth dilemma developed in Kenya by the author (3). ${ }^{3}$ The sample $2 S$ s received a moral judgment interview containing two dilemmas (developed by the author) focused on parent-child obligations and a set of three questions about the rights and wrongs of suicide (3).

The moral judgment interviews were stage-rated by the global method (4, 10 ) in order to compute a weighted average, the Moral Maturity Quotient $(M M Q)$, with major stage counting $75 \%$ and minor stage $25 \%$.

Forty interviews (20 sample 1, 20 sample 2 ) were independently coded a second time. Correlations of $M M Q$ between coders (sample $1 r=.85$, sample 2 $r=.86$ ), as well as levels of percentage agreement, ${ }^{4}$ (sample $195 \%$, sample 2 $90 \%$ ) indicate satisfactory intercoder reliability.

Descriptive and background information on $S \mathrm{~s}$ was obtained during the interview. In addition, the University of Nairobi Registrar provided records of grades for all courses taken by university $S$ s, and the Kenya Ministry of Education supplied 1973 O-level test scores on the secondary $S$ s. Olevels are standardized achievement examinations administered nationally every year to fourth form students to determine who can attend forms five and

\footnotetext{
${ }^{3}$ Thirty-one of the university $S_{S}$ were presented all four stories, while the remaining 21 received only two or three of the dilemmas. However, statistical comparison of the latter group with the former suggests that the varying number of dilemmas introduced no systematic bias (either upward or downward) into the moral judgment scoring.

${ }^{4}$ Here agreement, following Haan, Smith, and Block (6), has been defined as full agreement, agreement on the major stage designation, or simple reversal of the major and minor stage designation.
} 
six and, ultimately, the university. Every student in sample 2 took tests in English language, mathematics, biology, and in other subject areas selected by the student.

\section{Results}

\section{Sample 1 (University)}

The $M M Q$ s of the University $S$ s ranged from 200, stage 2, to 425, stage 4 (5). The correlation of $M M Q$ with the school experience, demographic, home background, and academic achievement measures is displayed in Table 1.

TABLE 1

Means, $S D$ S, and Correlations of Variables WITH MORAL MatURITY QUOTIENTS (MMQ)

\begin{tabular}{llllll}
\hline Variable & $M$ & $S D$ & $\boldsymbol{r}_{M M Q}{ }^{\mathrm{a}}$ \\
\hline
\end{tabular}

Sample 1: University students

\section{$M M Q$}

Time away from home (years)

Years at multiracial, multitribal secondary school

Father's education (years of school)

Mother's education (years of school)

Age (years)

Sex ( $0=$ female, $1=$ male $)$

Race $(0=$ African, $1=$ Asian $)$

Year at university (1-4)

First year grade point average at university

Overall grade point average at university
298.56

6.40

2.10

6.42

3.92

22.73

0.67

0.33

2.27

49.87

54.62
60.72

3.57

2.40

5.65

4.25

2.40

0.47

0.47

0.84

14.21

6.69

$0.35^{* *}$
0.03
-0.00
0.08
0.22
-0.03
-0.14
$0.33^{*}$
0.08
0.06

Sample 2: Secondary students

\section{$M M Q$}

Residence at school ( $0=$ day, 1 = boarding)

Multiethnic school ( $0=$ no, 1 = yes)

Father's education (years of school)

Mother's education (years of school)

Age (years)

Sex $(0=$ female, $1=$ male $)$

English achievement score (English 0-level) ${ }^{b}$

Math achievement score (Mathematics 0-level)

Science achievement score (Biology 0-level)

Overall achievement score (Total 0-levels)

\begin{tabular}{rrr}
224.38 & 55.61 & - \\
0.50 & 0.51 & 0.08 \\
0.50 & 0.51 & $0.42^{* *}$ \\
5.98 & 4.71 & $0.32 *$ \\
4.00 & 3.98 & 0.23 \\
17.53 & 1.34 & -0.27 \\
0.50 & 0.51 & -0.24 \\
5.68 & 2.07 & 0.26 \\
7.90 & 1.84 & 0.19 \\
6.68 & 1.76 & 0.05 \\
37.22 & 9.35 & 0.24 \\
\hline
\end{tabular}

Note: All tests of significance are two-tailed.

a For university sample, $d f=51$; for Secondary, $d f=39$.

b The Kenyan $\mathrm{O}$-level tests are scored to have lower scores be better than higher scores. I have reversed the signs of the four $\mathrm{O}$-level correlations with $M M Q$ so that positive signs indicate the expected relationship (i.e., higher scores going with higher $M M Q \mathrm{~s}$ ).

$* p<.05$. 
The three hypotheses of the study imply that time spent living independently, time spent at ethnically diverse secondary schools, and family modernization should correlate positively with stage of moral judgment. The measure of time away from home did significantly predict $M M Q(p<.01$ However, the other two expected relationships did not appear. Perhaps the effect of secondary school diversity was overridden by the more recent effect of the tremendous value diversity encountered by everyone at the University of Nairobi. The measure of exposure to university life, year at university, did relate significantly $(p<.05)$ to $M M Q$. Year at university and time away from home were not themselves at all correlated $[r(51)=.03]$.

This finding for time away from home is not likely to be the spurious result of an intervening relationship with $I Q$, which was not measured in this study. For one thing, time away from home was negatively related to academic success at the university: with first year grade point average $r(51)=-.10$, and with overall grade point average $r(51)=-.40$. Rather, time away from home was most related to having come from a rural community; that is, the rural students generally went away to school, while urban students attended schools in their city or town. As a result, $M M Q$ was somewhat negatively related to the number of years students had spent in urban areas $[r(51)=$ $-.14, p=\mathrm{ns}$ ], while time away from home was strongly negatively related to years in urban areas $[r(51)=-.51, p<.001$, two-tailed].

It is also of note that for this sample of intellectually elite non-Western university students, none of the demographic variables (age, sex, race) significantly predicted moral judgment stage.

\section{Sample 2 (Secondary)}

The $M M Q$ s of the secondary students were somewhat lower than those of the older university students. Scores ranged from 125, stage 1 (2), to 325, stage 3 (4). The correlation of $M M Q$ with school experience and other independent variables is presented in Table 1.

The hypotheses focus on the relationship between $M M Q$ and pluralistic school, residence, and family modernization. Both pluralistic school and family modernization were significantly correlated on the zero-order level to $M M Q$, but residence was not. There are two measures of modernization, father's and mother's education; of the two, father's education was the more highly correlated with $M M Q$.

Table 1 indicates that the relationship between $M M Q$ and age was negative, in violation of expectation. This finding probably results from an intervening negative correlation between age and father's education $[r(39)=$ 
$-.37, p<.05$, two-tailed], a pattern resulting from the greater ability of educated people in Kenya to find work and pay their children's school fees. Less educated parents often must struggle harder and delay until their children are older. When the effect of father's education is partialled out, the negative correlation between age and $M M Q$ reduces substantially, from $r$ (39) $=-.27$ to $r$ partial $(38)=-.17, p=n s)$.

Table 1 also indicates a positive relationship between $M M Q$ and $S$ s' academic ability, as measured by their standardized achievement test scores. Of the three achievement tests in English, Math, and Science, it is the English language score which best predicted $M M Q$. This suggests that verbal reasoning and competence in the English language, rather than mathematical and scientific abilities, were important to performance during the moral judgment interview. Of course, the three achievement tests were strongly intercorrelated $[r \mathrm{~s}(39)=.25, .56, .46]$ and all three contributed heavily to the overall measure $(r \mathrm{~s}$ with overall achievement $=.68$ for English, .51 for Math, and .83 for Science). While it is certainly likely that academic achievement is related to intelligence, in the way that it would be for a sample of Western school children, it is important to note that for this sample, academic achievement is not confounded with parents' education, in the way it almost invariably is in U.S. studies. Rather, students whose parents had had little schooling scored just as well on the overall achievement measure as students whose parents had had much education (overall achievement correlates $r(39)=.02$ with father's education, -.12 with mother's education). Given this total lack of relationship between parents' education and overall achievement, it is not likely that $I Q$ (not measured) was confounded with family modernization. Thus, it is not probable that the positive relationship found between moral judgment stage and father's education can be explained away as the spurious effect of a relationship between moral stage and $S$ s' $I Q$.

The secondary sample was designed for a three-way analysis of variance, residence $\times$ multiethnic school $\times$ sex. This analysis yielded a significant main effect for pluralistic school $[F(1,32)=8.35, p=.01]$ but not for residence $[F$ $(1,32)=.30, p=\mathrm{ns}], \operatorname{sex}[F(1,32)=2.69, p=.11]$ or any interactions. Yet multiethnic school was itself positively correlated to two variables which could perhaps be mediating its relationship with $M M Q:(a)$ father's education $[r(39)=.39, p=.01$, two-tailed $]$ and $(b)$ verbal ability, as measured by English achievement scores $[r(39)=.27, p=.10$, two-tailed]. Therefore, an analysis of covariance was performed with the latter two variables treated as covariates and their effect removed (partialled out) before the effect of the three major factors was tested. In this analysis the effect of the covariate, father's 
education, was sizable $[F(1,30)=3.07, p=.09]$, yet the factor of multiethnic school retained its significant effect $[F(1,30)=4.30, p=.04]$. No other covariates, factors, or interactions between factors were significant predictors.

The secondary sample thus yielded findings which supported hypotheses concerning parents' education and the experience of attending ethnically diverse schools but not the hypothesis concerning living away from home.

\section{Discussion}

This study has explored the possible role of social experience in cognitivemoral development. By relating the moral judgment level of two age groups of Kenyan students to antecedent variables, it has tested three hypotheses about home and school experiences. The data are correlational and therefore the study cannot establish causality, but the relationships that have been found are compatible with arguments that social experiences influence developmental change.

The first hypothesis was that students from more modernized backgrounds would show higher judgment levels than students from traditional backgrounds, because modernization brings with it child-rearing practices that encourage a greater independence of adult constraint. The results found modernization (father's education) to significantly predict moral judgment scores for the younger (secondary) but not the older (university) sample. The different results for the two samples may perhaps be due to the relative degree of power and influence that parents bear over secondary versus college-aged children.

The second hypothesis was that degree of contact by students with cultural diversity at school would relate to moral judgment level, because the encounter with value pluralism can provoke moral questioning and reevaluation. The findings revealed that contact with diversity did significantly predict moral judgment level for the younger sample, even after controlling for father's education and English achievement scores. However, it was not significantly related for the university students, though almost half of them discussed this type of experience in a retrospective interview. The data, therefore, offer some, but not complete, support for Turiel's (19) hypothesis that encountering cultural pluralism can stimulate the development of moral reasoning. It should be noted, however, that in this study they could not do so by promoting the development of principled (stages 5 and 6) reasoning, as Turiel hypothesized. That is, because there were almost no stage 5 or $6 S \mathrm{~s}$ in the Kenyan sample, the results obtained must explain development among 
stages 1 to 4 . The interview material collected upon the university students suggested how encountering cultural pluralism may foster the development of conventional (stages 3 and 4) reasoning out of preconventional (stages 1 and 2) positions. To judge from the interviews (3), the experience of meeting people from other cultural backgrounds may have helped students to realize that the moral values of their own culture represent a coherent system of roles, rights, and obligations; they might for the first time, have begun to think of morality in terms of a system of rules (characteristic of the shift from preconventional to conventional morality). A sense of loyalty to their own system, typical of stages 3 and 4, may have been engendered to replace the more individualistic perspective of stages 1 and 2 .

The hypothesis merits further investigation, with special attention paid to the moral atmosphere of the school. Following Garbarino and Bronfenbrenner (5), I believe that the encounter with value diversity must occur in a setting where the child meets partially competing, partially overlapping values in a positive setting, for it to stimulate moral reasoning. In the case of Kenyan schools, this means the members of different cultural groups must feel respect for one another and must be close enough (in the participants' minds) to influence the content of each other's moral values. A child must experience cognitive disequilibrium caused by the fact that other children, whom he or she cares about, have somewhat different moral ideas. If the groups merely coexist, with each side agreeing that the other has totally "strange," "funny," or "stupid" ideas, then the cultural diversity will present no cognitive problem to the participants. There will be no attempt to reconcile the conflicting points of view through a more complex understanding of morality. As far as I could judge, the culturally mixed schools that I visited in Nairobi did embody such a positive atmosphere, though it was more evident at some schools than at others.

Finally, the third hypothesis was that students who lived independently away from home would show higher moral judgment levels than students who lived at home, because independent living tends to provoke reflectiveness, as well as to provide greater opportunity for free discussion and cooperative exchange by peers in the student living quarters. Amount of independent living was found to relate significantly to moral judgment level for the university but not the secondary sample.

This issue also merits further investigation, with special attention paid to the disciplinary conditions of the home which the child is leaving behind. That is, the stimulating effect of leaving home might be expected to be strongest for children whose parents typically use "power assertion" techniques rather than 
"induction," or reasoning, to persuade them what to do (7). The contrast between home and "independent" living would be most striking for such children. In Kenya, children from more traditional families would of course be those expected to be most affected by living independently.

This study, in sum, suggests ways in which social experience stimulates the development of moral reasoning. More specifically, it suggests influences facilitative of the emergence of conventional reasoning (stages 3 and 4) out of preconventional reasoning (stages 1 and 2). Because most of the world's adults are probably in fact conventional moral reasoners, it is vital to try to understand the processes by which this type of thinking develops.

\section{REFERENCES}

1. Bronfenbrenner, U. The role of age, sex, class and culture in studies of moral development. Relig. Educ., 1962, 57, 3-17.

2. Denney, N. D., \& DufFy, D. M. Possible environmental causes of stages in moral reasoning. J. Genet. Psychol., 1974, 125, 277-283.

3. EDWARDS, C. P. The effect of experience on moral development: Results from Kenya. (Doctoral dissertation, Harvard Graduate School of Education, 1974). Ann Arbor, Mich.: University Microfilms, 1975, No. 75-16860.

4. Societal complexity and moral development: A Kenyan study. Ethos, 1975, 3, 505-527.

5. Garbarino, J., \& Bronfenbrenner, U. The socialization of moral judgment and behavior in cross-cultural perspective. In T. Lickona (Ed.), Moral Development and Behavior. New York: Holt, Rinehart \& Wiıston, 1976.

6. HAAN, N., SMITH, M. B., \& BLOCK, J. The moral reasoning of young adults: Political social behavior, family background and personality correlation. J. Personal. \& Soc. Psychol., 1968, 10, 183-201.

7. Hoffman, M. L., \& Saltzstein, H. D. Parent discipline and the child's moral development. J. Personal. \& Soc. Psychol., 1967, 5, 45-57.

8. HoLstein, C. B. The relation of children's moral judgment level to that of their parents and to communications patterns in the family. In R. C. Smart \& M. S. Smart (Eds.), Readings in Child Development and Relationships. New York: Macmillan, 1972.

9. Keasey, C. B. Social participation as a factor in the moral development of preadolescents. Devel. Psychol., 1971, 5, 216-220.

10. KohLBERG, L. The development of modes of moral thinking and choice in the years 10 to 16. Unpublished Doctoral dissertation, University of Chicago, Chicago, Illinois, 1958.

11. Stage and sequence: The cognitive-developmental approach to socialization. In $D$. Goslin (Ed.), Handbook of Socialization. New York: Rand McNally, 1969.

12. Kugelmass, S., \& Breznitz, S. The development of intentionality in moral judgment in city and kibbutz adolescents. J. Genet. Psychol., 1967, 111, 103-111.

13. Lickona, T. Research on Piaget's theory of moral development. In T. Lickona(Ed.), Moral Development and Behavior. New York: Holt, Rinehart \& Winston, 1976.

14. Parikh, B. S. Moral judgment development and its relation to family environmental factors in Indian and American upper middle class families. Unpublished Doctoral dissertation, Boston University, School of Education, Boston, Massachusetts, 1975.

15. Piaget, J. The Moral Judgment of the Child. London: Routledge \& Kegan Paul, 1932. 
16. Porteus, B. D., \& Johnson, R. C. Children's responses to two measures of conscience development and their relation to sociometric nomination. Child Devel., 1965, 36, 703711.

17. Shoffeits, P. G. The moral development of children as a function of parental moral judgments and child rearing. Unpublished Doctoral dissertation, George Peabody College of Teachers, Nashville, Tennessee, 1971.

18. Turiel, E. Stage transition in moral development. In R. M. Travers (Ed.), Second Handbook on Research on Teaching. Chicago: Rand McNally, 1972.

19. Conflict and transition in adolescent moral development. Child Devel., 1974, 45, 14-29.

20. Whiting, B. B. Work and the family-Cross-cultural perspective. Paper prepared for Women: Resource for a Changing World, an International Conference, Radcliffe Institute, Cambridge, Massachusetts, 1972.

21. The effect of modernization on socialization. Paper presented at the annual meeting of the Society for Cross-Cultural Research, Boston, Massachusetts, 1974.

School of Education

University of Massachusetts-Amherst

Amherst, Massachusetts 01003 